Journal of Applied Pharmaceutical Science Vol. 6 (03), pp. 111-115, March, 2016

Available online at http://www.japsonline.com

DOI: 10.7324/JAPS.2016.60319

ISSN 2231-3354 (cc) BY-NC-SA

\title{
The Effects of Short-term Circuit Resistance Training with Supplementation of Milk, Cheese Juice, Whey Protein on Resting Level Apolipoprotein M- HDL Total Cholesterol, Lipid Profile, Gastric Inhibitory Polypeptide and Plasma Estradiol in Untrained Young Men
}

\author{
Aalizadeh Ali ${ }^{1}$, Ramezani Hossein ${ }^{2}$, Abdi Ahmed ${ }^{3}$, Rohbakhsh Ebad ${ }^{4}$, Changizi Ashtiyani Saeed ${ }^{5}$, Ghanbari Niaki \\ Abbas ${ }^{6} *$ \\ ${ }^{1}$ The Persian Gulf Marine Biotechnology Research Center, the Persian Gulf Biomedical Research Center, Bushehr University of Medical Sciences, \\ Bushehr, Iran. ${ }^{2}$ Exercise Physiology Research Unit, Babol University of Medical Sciences, Babol, Iran. ${ }^{3}$ Departments of Clinical Biochemistry and \\ Biophysics Unit, Faculty of Medicine Babol University of Medical Sciences, Babol, Iran. ${ }^{4}$ Exercise Physiology Research Unit, Department of Education \\ Baboulsar, Mazandaran, Iran. ${ }^{5}$ Department of Physiology, Arak University of Medical Sciences, Arak, Iran. ${ }^{6}$ Exercise Biochemistry Branch, Faculty of \\ Physical Education \& Sport Sciences, University of Mazandaran, Baboulsar, Mazandaran, Iran.
}

\begin{tabular}{l} 
ARTICLE INFO \\
\hline Article history: \\
Received on: $12 / 07 / 2015$ \\
Revised on: 03/10/2015 \\
Accepted on: 12/12/2015 \\
Available online: $30 / 03 / 2016$ \\
\hline Key words: \\
Lipoprotein, plasma \\
estradiol, apolipoprotein M, \\
untrained young men.
\end{tabular}

\begin{abstract}
Cardiovascular diseases are the most significant factors leading to death. This quasi-experimental study was carried out on 28 non athletic men. Subjects were divided into 4 groups. To the first group water (400 cc) was given, the second group received whey protein supplementation $(50 \mathrm{~g})$, the third group had cheese juice $(50 \mathrm{~g})$, and milk was given to the fourth one $(400 \mathrm{cc})$, immediately after the training session. High-density lipoprotein (HDL), its sub fractions HDL2 and HDL3 cholesterol, apolipoprotein M, gastric inhibitory polypeptide and estradiol were evaluated prior to and after training for 12 sessions, three sessions in each week. The differences were not significant for gastric inhibitory polypeptide (GIP) and estradiol in the fourth group after training in comparison with the first phase. A significant decrease in apolipoprotein M- HDL total cholesterol on resting level were observed in all four groups and in HDL3 cholesterol with cheese juice and also whey protein in comparison with prior phase (P-values were $0.02,0.001,0.000,0.015$, respectively) $(0.01,0.01)$. A significant increase in HDL2 cholesterol level was observed in the groups with cheese juice and whey protein in comparison with their prior phases (P-values were $0.02,0.03$, respectively). This study showed that circuit resistance training has positive effects on the lipid profile changes in untrained young men.
\end{abstract}

\section{INTRODUCTION}

Obesity is considered as a risk factor for, cardiovascular diseases specially because it increases blood cholesterol and results in high blood pressure. Overweight and obesity are multi factorial phenomena in which genetic and environmental factors

\footnotetext{
* Corresponding Author

Abbas Ghanbari Niaki, Exercise Biochemistry Branch, Faculty of Physical Education \& Sport Sciences, University of Mazandaran, Baboulsar, Mazandaran, Iran. Email: Ghanbara[atlumz.ac.ir
}

as well as lifestyle are involved. In fact, in developed countries physical inactivity and poor diet are the causes of obesity and cardiovascular diseases (Dridi et al., 2009). Resistance training, in addition to increasing strength and muscle mass, can have beneficial effects on risk factors associated with cardiovascular diseases and can contribute to the effective prevention of cardiovascular diseases (Sheykholeslami et al., 2009). Human studies have indicated a significant inverse relationship between HDL-C levels, the major protein apolipoprotein A-I (APOA-I) and heart-coronary diseases (atherosclerosis) (Ghanbari-Niaki et al., 2007; Khabazian et al., 2009; Khabazian et al., 2008). 
The role of HDL-C in the prevention of cardiovascular disease through the transfer of excess cholesterol from peripheral cells and carrying it to the liver is exerted during a process called reverse cholesterol transport (RCT) (Khabazian et al., 2008). The apolipoprotein constituents are made from the major plasma lipoproteins which regulate lipoprotein metabolism and determines the unique role of these lipoproteins in cholesterol transport and lipid metabolism (Davidsson et al., 2010; Dominiczak et al., 2011).

Apo lipoprotein M (Apo-M) is a novel human protein of apolipoprotein classes with 188 amino acids that are identified, characterized and highly expressed in liver and kidney tissues. Apo-M is mainly associated with HDL-C in human plasma small amounts of which are also available in rich triglyceride lipoprotein and low-density lipoproteins (LDL) (Todiodi et al., 2007).

HDL particles containing Apo-M isolated from human plasma are of two types in size, weight and density. Lipid composition of human HDL containing Apo-M is similar to total HDL (Sevvana et al., 2007). The level of Apo-M in plasma/serum is affected by several factors such as pregnancy, hyperglycemia, plasma leptin concentration, obesity, diabetes, and insulin concentration (Kujiraoka et al., 2013; Lamant et al., 2006; O'Bryan et al., 2004; Xu et al., 1999; Segrest et al., 2013; Song et al., 2012; Ghanbari Niaki et al., 2007). In human plasma, 5\% of the HDL particles contain Apo-M. Although there is not Apo-M in all HDL particles, investigation has shown that they are available as positive association between plasma levels of Apo-M and HDLcholesterol concentrations in humans (Christoffersen et al., 2008). Estrogens are a group of steroidal compounds containing estrone, estradiol, and estriol that act as the growth regulating hormones and reproduction hormones (Todiodi et al., 2008).

Studies showed that the prevalence of cardiovascular disease in postmenopausal women who received estrogen alone or in combination with progesterone was less than other treatments. In this respect it seems that hormone 17 beta-estradiol (estrogen) may reduce low-density lipoprotein (LDL), and may lead to increased levels of HDL-C, increased coronary vasodilatation, improved glucose metabolism and decreased plasma insulin levels, which are important for the prevention of heart disease(Babiker et al., 2009). Gastric inhibitory polypeptide (GIP) and gastric inhibitory polypeptide-1 (GIP-1) are known as important intestinal hormones that are essential for normal glucose homeostasis (Ugleholdt et al., 2009). Few studies have been carried out on the GIP effects on cardiovascular system. However, studies on the effects of GIP in the regulation of blood flow have been reported. Also, referring to the endothelium, the results have shown that GIP production of nitric oxide from endothelial cells stimulates the portal vein (Nie et al., 2012).

The effects of different types of regular aerobic exercises and, to some degree, those of resistance training on plasma lipids, lipoproteins, particularly on high density-lipoprotein (HDL) and its compositions have been well documented. However, the effects of circuit resistance training (CRT) with or without milk, Cheese juice, whey protein products on the resting level apolipoprotein MHDL total cholesterol in, lipoprotein levels, and GIP and plasma estradiol have not been studied yet. This study was conducted to investigate the effect of a 4 week- -CRT program with or without supplementation of milk, cheese juice, whey protein on resting level apolipoprotein M- HDL total cholesterol, lipoprotein levels, and GIP and plasma estradiol in untrained young men.

\section{MATERIALS AND METHODS}

The study was approved by the ethics committee of the University of Mazandaran (UMZ) and Babol University of Medical Sciences (BUMS) in Mazandaran, Iran in accordance to the declaration of the Iranian Ministry of health.

\section{Subjects}

A written consent was obtained from all 28 young male and untrained high schools students (age 21.6 $\pm 0.44 \mathrm{y}$, height $172.66 \pm 1.45 \mathrm{~cm}$, body weight $70.8 \pm 6.5 \mathrm{~kg}$, and body mass index (BMI)of $20.19 \pm 1.70 \mathrm{~kg} / \mathrm{m} 2$ ) without any weight circuit-resistance training experiences who were employed and randomly assigned to four groups: training-water ( $\mathrm{TW}, \mathrm{n}=7)$, training-milk (TM, $\mathrm{n}=7$ ), training- cheese juice (TCJ, $n=7$ ), and training- whey protein (TWP, $n=7)$. Subjects received either tap water $(400 \mathrm{cc}$ ) or low fat milk (400cc), or whey protein supplementation $(50 \mathrm{~g})$ or cheese juice $(50 \mathrm{~g})$, immediately after training sessions. It should be noted that the solution has gradually been administrated.

\section{Training protocol and Statistical analysis}

The circuit resistance training was performed according to Ghanbari Niaki (2006) and Ghanbari Niaki et al., (2007) with a little modification in the number of exercises (bench press-off pins, inclining bench press, cable push-down, dead lift halter, squat $90^{\circ}$ over neck, Roman chair back extension, crunch with free weight, leg press, leg extension, seated calf raise). Subjects were asked to perform circuit resistance training for 45-50 minutes/session, 3 days/week and for 4 weeks. Each training session consisted of warm-up (10min), cool-down (10min), and circuit resistance of 10 exercises ( 25 seconds for each exercise, 812 repeats, and 2 rounds/session with 5 minutes rest period between rounds) to strengthen most of the large muscle groups. Each load corresponded to $60 \%$ of one repetition maximum. All exercises were conducted with the use of free weight and machine. The subjects were instructed to follow a normal lifestyle, to maintain daily habits, to avoid any medications, and to refrain from exercise 3 days before the blood sampling.

Blood samples were obtained from an antecubital vein 72 hours before and 72 hours after the last circuit resistance training session while the subjects fasted overnight (at least 12h). Plasma samples were immediately frozen and stored at $-20^{\circ} \mathrm{C}$ and $-80^{\circ} \mathrm{C}$ for subsequent analyses (within 4-6 weeks). Plasma Apo-M was determined by using a commercial human Apo-M, ELISA Kit (Catalog Number-CSBEL001947HU, CUSABIO-BIOTECH, China) with detection range of $1.56 \mathrm{ng} / \mathrm{ml}-100 \mathrm{ng} / \mathrm{ml}$, and the sensitivity of $0.39 \mathrm{ng} / \mathrm{ml}$. To measure HDL3 cholesterol sedimentary method and enzymatic assays were used with Pars 
azmon company kits/ Iran. HDL2 levels obtained HDL2= -HDL3 method. HDL2 cholesterol levels were determined using the difference between HDL and HDL3 cholesterol .GIP Plasma level was measured by Elisa immunoassay enzyme method for which Cusabio Biotech company kits/China were used. Plasma estradiol concentration was determined by ELISA (Diagnostics Biochem Canada Inc., Ontario, Canada).After normalization of the data by suitable test, dependent and independent t-tests were employed. All the data were reported as mean \pm SE. A significant difference was accepted at alpha $\mathrm{P} \leq 0.05$. All statistical analyses were performed with SPSS (Version 18; SPSS, Chicago, IL).

\section{Preparation of cheese juice extract}

At first $3 \mathrm{~kg}$ of milk was heated at the temperature of 100 degrees, then the heat was reduced to prevent it from reaching its boiling point .After that from a mixture of 50 grams of vinegar with 10 grams of salt and 50 grams of yogurt, which were already prepared, were gently added to the surface of the boiling milk with a spoon. In this case milk is divided into two layers, the upper layer was cast away and the solid part after filtration and dewatering was kept in the fridge. After each training session, 50 grams of it would be mixed with water and consumed.

\section{RESULTS AND DISCUSSION}

The densities of the measured variables are shown in Table 1. Data analysis showed that apolipoprotein M- HDL total cholesterol levels in 4 groups significantly decreased, while HDL2-C and HDL3-C levels in TCJ and TWP groups had significant increase and decrease, respectively (P-values were $0.02,0.03,0.01,0.01,0.001,0.002,0.001$, and 0.004 , respectively) (Table 1).

The above data provided some support for the hypothesis that physical activity and exercise could be utilized to improve Cholesterol levels. Regular physical activity has been shown to increase HDL2-C cholesterol and to decrease HDL3-C and apolipoprotein M- HDL total cholesterol levels significantly.

Despite various studies on the effect of exercise on the levels of plasma apolipoproteins including apolipoprotein AI (Khabazian et al., 2009), no study has been carried out to examine the effect of exercise on the levels of Apo-M. The results of the present study, however, showed that doing a 4-weeks resistance training reduced the levels of plasma Apo-M. Descriptive studies on human tissue have shown that Apo-M mainly in the liver and kidney and in smaller amounts can be found in the fetal kidneys and liver.

Thus, Apo-M may have a special function in the body, which may be associated with hepatic lipid metabolism and lipoprotein (Luo et al., 2009). Recently it has been shown that in obese individuals, plasma levels of Apo-M is positively associated with plasma leptin level and negatively with the level of cholesterol. Indeed, it is suggested that leptin can stimulate liver cells to produce Apo-M. Moreover, leptin and its receptor are essential for the expression of Apo-M (Xu et al., 2004).
Table 1: The mean \pm SE of serum concentration in pre-test and post-test.

\begin{tabular}{|c|c|c|c|}
\hline Variable & Groups & $\begin{array}{c}\text { Before Exercise } \\
\text { Mean } \pm \text { SD }\end{array}$ & $\begin{array}{c}\text { After Exercise } \\
\text { Mean } \pm \text { SD }\end{array}$ \\
\hline \multirow{4}{*}{$\begin{array}{l}\text { Apolipoprotein M- } \\
\text { HDL-c (ng /ml ) }\end{array}$} & TW & $10.26 \pm 4.66$ & $5.73 \pm 2.48^{*}$ \\
\hline & $\mathrm{TM}$ & $20.53 \pm 4.462$ & $4.46 \pm 1.11^{*}$ \\
\hline & TCJ & $17.43 \pm 2.65$ & $4.88 \pm 1.42^{*}$ \\
\hline & TWP & $11.18 \pm 5.26$ & $2.80 \pm 1.29^{*}$ \\
\hline \multirow{4}{*}{ HDL2-C(mg/dl) } & TW & $16.07 \pm 3.64$ & $16.07 \pm 3.88$ \\
\hline & TM & $19.38 \pm 3.81$ & $20.00 \pm 2.97$ \\
\hline & TCJ & $14.47 \pm 3.09$ & $19.92 \pm 2.53^{*}$ \\
\hline & TWP & $13.48 \pm 4.31$ & $18.66 \pm 3.07^{*}$ \\
\hline \multirow{4}{*}{ HDL3-C(mg/dl) } & TW & $23.51 \pm 3.60$ & $33.35 \pm 5.34$ \\
\hline & $\mathrm{TM}$ & $30.30 \pm 5.79$ & $33.04 \pm 4.31$ \\
\hline & TCJ & $30.14 \pm 5.71$ & $27.82 \pm 4.74^{*}$ \\
\hline & TWP & $27.67 \pm 5.55$ & $25.98 \pm 6.44^{*}$ \\
\hline \multirow{4}{*}{ Estradiol (pg /ml) } & TW & $69.85 \pm 14.67$ & $66.00 \pm 23.30$ \\
\hline & $\mathrm{TM}$ & $68.71 \pm 17.63$ & $60.42 \pm 16.46$ \\
\hline & TCJ & $64.57 \pm 20.80$ & $65.28 \pm 14.70$ \\
\hline & TWP & $55.28 \pm 9.46$ & $56.42 \pm 14.02$ \\
\hline \multirow{5}{*}{$\mathrm{GIP}(\mathrm{ng} / \mathrm{ml})$} & TW & $42.37 \pm 45.35$ & $35.21 \pm 22.28$ \\
\hline & $\mathrm{TM}$ & $32.90 \pm 29.37$ & $17.50 \pm 8.63$ \\
\hline & TCJ & $27.45 \pm 24.06$ & $19.94 \pm 12.58$ \\
\hline & TWP & $58.47 \pm 53.40$ & $31.90 \pm 17.25$ \\
\hline & \multicolumn{3}{|c|}{$\begin{array}{l}\text { HDL: High-density lipoprotein cholesterol, HDL2 } \\
\text { and HDL3 cholesterol, GIP: Gastric inhibitory } \\
\text { polypeptide, } \\
\text { Training cheese juice: TCJ, Training Milk: TM } \\
\text { Training-Water: TW, Training whey protein: TWP. } \\
\text { (* Inter a group difference at } \mathrm{P} \leq 0.05) \text {. }\end{array}$} \\
\hline
\end{tabular}

In a study Lappalainene et al., (2009) showed that eccentric intense isokinetic exercise significantly reduced leptin levels. Although in the present study the levels of leptin were not measured, the reduced leptin levels might have happened as a reduction mechanism of Apo-M. However, the study reported that estrogen in vivo and in vitro conditions by a series of mechanisms upregulated the Apo-M (Wei et al., 2011). In this study, one of the possible reasons for low levels of Apo-M may be the decreased estrogen levels; So, the reduction of Apo-M in exercise and milk consumption group may be associated with estradiol further reduction.

In this study, levels of HDL2, increased significantly in the exercise groups with whey protein consumer and with cheese juice consumer in comparison to other groups, Although HDL3 level, increased significantly in the exercise groups with milk and water consumers in comparison with other groups. Indeed, a positive correlation between the levels of LDL cholesterol and cardiovascular disease was observed as well as an inverse relationship between HDL cholesterol and atherosclerosis (Ahnstrom et al., 2009). HDL particles, through their antiinflammatory and anti-oxidative activities act as anti-atherogenic agents. HDL particles, as a mediator for the return of tissue Cholesterol to the liver for bile secretion, protect against atherosclerosis .

Yktayar et al., (2011), in their study on the effects of resistance training, endurance and combination on lipid profiles and non-athletic middle-aged men reported that resistance exercise increased the levels of HDL. Studies done by Ghanbari Niaki et al., (2011), showed that a single bout of circle resistance exercise training increased the levels of plasma HDL-C in female students. 
Teixeira et al., (2012), in their study on the effect of resistance exercise with and without whey protein on biochemical parameters of lipid metabolism and risk of cardiovascular disease in animal models showed that resistance training combined with whey protein could improve the lipid profile, lower total cholesterol and non-HDL cholesterol but whey protein without resistance training significantly increased HDL cholesterol concentrations which is consistent with the present research. However, in this study, no significant changes in the levels of estradiol and estradiol were observed in the milk consumption exercise group and water consumption exercise group compared with the pre-test.

17 beta-estradiol hormone (estrogen) by reducing LDL, increasing HDL levels, increasing coronary vasodilatation, improving glucose metabolism and decreasing plasma insulin levels, may have an important role in preventing heart diseases. (Babiker et al., 2009). It is reported that estradiol increases during exercise however, it is reduced significantly after exercise (Ives et al., 2011).The results showed that although consumer resistance training and supplements (especially whey protein) caused a slight reduction in GIP plasma levels, the changes in GIP plasma in pretest and post-test showed no significant difference between the study groups that is consistent with a number of studies (Mortensen et al., 2012).

Solomon et al., (2010) studied the effect of a diet with a low or high glycemic index along with aerobic exercise (walking on a treadmill or cycling for 60 minutes per session, 5 days a week with a maximum heart rate of $85 \%$ for 12 weeks) on 22 obese patients with pre-diabetes. The results suggested that GIP response after food intake with lower glycemic index and exercise was delayed while these changes were not observed in the group with a high glycemic index diet with. Also, one possible reason for low levels of GIP in this study, might have been a lack of adequate stimuli such as glucose, On the other hand, since the level of GIP increases while food intake, the decrease in the plasma levels of GIP may happen over time and by its decreased plasma level.

\section{CONCLUSION}

The results showed that the combination of resistance training and protein composition in the milk group could affect lipid and lipoprotein profiles and could increase the levels of HDL particles which play an important role in the prevention of cardiovascular diseases.

\section{REFERENCES}

Ahnström, J. 2009. Apolipoprotein M-Studies of Structure and Function. Lund University.

Babiker FA, De Windt LJ, van Eickels M, Grohe C, Meyer R, Doevendans PA. Estrogenic Hormone Action in the Heart: Regulatory Network and Function. Cardiovascular Research, 2002; 53(3): 709-719.

Christoffersen Ch, Jauhiainen M, Moser M. Moser, B. Porse, C. Ehnholm, M. Boesl, B. Dahlback, L.B. Nielsen, Effect of Apolipoprotein $M$ on High Density Lipoprotein Metabolism and Atherosclerosis in Low Density Lipoprotein Receptor Knock-out Mice. J. Biol. Chem, 2008; 283(4): 1839-1847.
Davidsson P1, Hulthe J, Fagerberg B, Camejo G. Proteomics of Apolipoproteins and Associated Proteins from Plasma High-density Lipoproteins. Arteriosclerosis, Thrombosis, and Vascular Biology, 2010; 30(2): 156-163.

Dominiczak, M.H. and M.J. Caslake, Apolipoproteins: Metabolic Role and Clinical Biochemistry Applications. Annals of Clinical Biochemistry, 2011. 48(6): 498-515.

Dridi, S. and M. Taouis, Adiponectin and Energy Homeostasis: Consensus and Controversy. The Journal of Nutritional Biochemistry, 2009. 20(11): 831-839.

Ghanbari-Niaki A, Khabazian BM, Hossaini-Kakhak SA, Rahbarizadeh F, Hedayati M. Treadmill Exercise Enhances ABCA1 Expression in Rat Liver. Biochemical and Biophysical Research Communications, 2007; 361(4): 841-846.

Ghanbari-Niaki, A., S. Nabatchian, and M. Hedayati, Plasma Agouti-related Protein (AGRP), Growth Hormone, Insulin Responses to a Single Circuit-Resistance Exercise in Male College Students. Peptides, 2007. 28(5): 1035-1039.

Ghanbari-Niaki, A., M. Saghebjoo, and M. Hedayati. A Single Session of Circuit-resistance Exercise Effects on Human Peripheral Blood Lymphocyte ABCA1 Expression and Plasma HDL-C Level. Regulatory Peptides, 2011. 166(1): 42-47.

Ghanbari-Niaki, A. Ghrelin and Glucoregulatory Hormone Responses to a Single Circuit Resistance Exercise in Male College Students. Clinical Biochemistry, 2006. 39(10): 966-970.

Ives SJ, Blegen M, Coughlin MA, Redmond J, Matthews T, Paolone V. Salivary Estradiol, Interleukin-6 Production, and the Relationship to Substrate Metabolism During Exercise in Females. European Journal of Applied Physiology, 2011. 111(8): 1649-1658.

Khabazian BM, Ghanbari-Niaki A, Safarzadeh-Golpordesari Ar, Ebrahimi M, Rahbarizadeh F, Abednazari H. Endurance Training Enhances ABCA1 Expression in Rat Small Intestine. European Journal of Applied Physiology, 2009. 107(3): 351-358.

Khabazian B.M., Ghanbari Niaki A., Rahbarizadeh F., Hoseini Kakhak A. and Jabari Noghabi M. The Effect of 6 Weeks of Endurance Training on the Expression of Hepatic ABCA1 in Male Wistar Rats. World Journal of Sport Sciences, 2008. 1(1): 01-7.

Kujiraoka T, Nakamoto T, Sugimura H, Iwasaki T, Ishihara M, Hoshi T, Horie Y, Ogawa K, Todoroki M, Nakatani Y, Banba N, Yasu T, Hattori H. Clinical Significance of Plasma Apolipoprotein F in Japanese Healthy and Hypertriglyceridemic Subjects. Journal of Atherosclerosis and Thrombosis, 2013. 20(4): 380-390.

Lamant M1, Smih F, Harmancey R, Philip-Couderc P, Pathak A, Roncalli J, Galinier M, Collet X, Massabuau P, Senard JM, Rouet P. ApoO, A Novel Apolipoprotein, Is an Original Glycoprotein Up-regulated by Diabetes in Human Heart. Journal of Biological Chemistry, 2006. 281(47): 36289-302.

Lappalainen Zekine, Kilinc Fatih, Lappalainen Jani, Atalay, Mustafa. Time-of-day Effects during Acute Isokinetic Exhaustive Eccentric Exercise: Serum Leptin Response. Isokinetics and Exercise Science, 2009. 17(1): 19-25.

Guanghua Luo, Xiaoying Zhang, Peter Nilsson-Ehle, and Ning Xu. Apolipoprotein M. Lipids Health Dis, 2004. 3(1): 21.

Mortensen LS, Holmer-Jensen J, Hartvigsen ML, Jensen VK, Astrup A, de Vrese M, Holst JJ, Thomsen C, Hermansen K. Effects of Different Fractions of Whey Protein on Postprandial Lipid and Hormone Responses in Type 2 Diabetes. European journal of clinical nutrition, 2012. 66(7): 799-805.

Nie Y, Ma RC, Chan JC, Xu H, Xu G. Glucose-dependent Insulinotropic Peptide Impairs Insulin Signaling via Inducing Adipocyte Inflammation in Glucose-dependent Insulinotropic Peptide Receptoroverexpressing Adipocytes. The FASEB Journal, 2012. 26(6): 2383-2393.

O'Bryan MK, Foulds LM, Cannon JF, Winnall WR, Muir JA, Sebire K, Smith AI, Keah HH, Hearn MT, de Kretser DM, Hedger MP. Identification of a Novel Apolipoprotein, ApoN, in Ovarian Follicular Fluid. Endocrinology, 2004. 145(11): 5231-5242.

Segrest, J.P., M.C. Cheung, and M.K. Jones, Volumetric Determination of Apolipoprotein Stoichiometry of Circulating HDL Subspecies. Journal of lipid research, 2013. 54(10): p. 2733-2744. 
Sevvana M, Ahnström J, Egerer-Sieber C, Lange HA, Dahlbäck B, Muller YA. Serendipitous Fatty Acid Binding Reveals the Structural Determinants for Ligand Recognition in Apolipoprotein M. Journal of Molecular Biology, 2009. 393(4): 920-936.

Sheykholeslami Vatani D, Ahmadi S, Mojtahedi H, Marandi M, Ahmadi Deharshid K, Faraji H, Gharibi F. Effect of moderate and high intensity resistant exercises on cardiovascular risk factors in non-athlete university students. Kowsar Medical Journal, 2011. 16(2): 115-121.

Solomon TP, Haus JM, Kelly KR, Cook MD, Filion J, Rocco M, Kashyap SR, Watanabe RM, Barkoukis H, Kirwan JP. A Lowglycemic Index Diet Combined with Exercise Reduces Insulin Resistance, Postprandial Hyperinsulinemia, and Glucose-dependent Insulinotropic Polypeptide Responses in Obese, Prediabetic Humans. The American Journal of Clinical Nutrition, 2010. 92(6): 1359-1368.

Song F, Poljak A, Crawford J, Kochan NA, Wen W, Cameron B, et al. Plasma Apolipoprotein Levels are Associated with Cognitive Status and Decline in a Community Cohort of Older Individuals. PloS one, 2012. 7(6): e34078.

Teixeira Kely Raspante, Silva Marcelo Eustáquio, Neves Leandro Xavier, Santos Rinaldo Cardoso dos, Pedrosa Maria Lúcia, Haraguchi Fabiano Kenji. Whey protein improves HDL/non-HDL ratio and body weight gain in rats subjected to the resistance exercise. Braz. arch. biol. technol. [Internet]. 2012 Dec [cited 2016 Feb 03] ; 55( 6 ): 943-950. Available from: http://www.scielo.br/scielo.php?script=sci_ arttext\&pid=S1516-89132012000600019\&lng=en. http://dx.doi.org/10.1590/S1516-89132012000600019.

Todiodi M. The Effects of Exogenous Estrogens on Estrogen Receptors in Male Reproductive Organs. Interdisciplinary Hournal of Health Sciences, 2010; 1(1): 73-82.

Ugleholdt, R., Glucose-dependent Insulinotropic Polypeptide (GIP): From Prohormone to Actions in Endocrine Pancreas and Adipose Tissue. Danish medical bulletin, 2011; 58(12): B4368-B4368.
Wei J, Shi Y, Zhang X, Feng Y, Luo G, Zhang J, Mu Q, Tang Y, Yu Y, Pan L, Nilsson-Ehle P, Xu N. Estrogen Upregulates Hepatic Apolipoprotein M Expression via the Estrogen Receptor. Biochimica et Biophysica Acta (BBA)-Molecular and Cell Biology of Lipids, 2011. 1811(12): 1146-1151.

Xu, N., P. Nilsson-Ehle, and B. Ahrén, Correlation of Apolipoprotein $\mathrm{M}$ with Leptin and Cholesterol in Normal and Obese Subjects. The Journal of Nutritional Biochemistry, 2004.15(10):p.579-582.

$\mathrm{Xu}, \mathrm{N}$. and B. Dahlbäck, A Novel Human Apolipoprotein (apoM). Journal of Biological Chemistry, 1999. 274(44): p. 31286-31290.

Yktayar M, Mohammadi S, Ahmadi Dhrshyd K, Khdamradpour M. Effects of Resistance Training, Endurance and Combination on Lipid Profiles and Non-athletic Middle-aged Men. Scientific Journal of Kurdistan University of Medical Sciences, 2012; 16: p. 36-26.

\section{How to cite this article:}

Aalizadeh A, Ramezani H, Abdi A, Rohbakhsh E, ChangiziAshtiyani S, Ghanbari-Niaki A. The Effects of Short-term Circuit Resistance Training with Supplementation of Milk, Cheese Juice, Whey Protein on Resting Level Apolipoprotein M- HDL Total Cholesterol, Lipid Profile, Gastric Inhibitory Polypeptide and Plasma Estradiol in Untrained Young Men. J App Pharm Sci, 2016; 6 (03): 111-115. 